\title{
miR-221-induced PUMA silencing mediates immune evasion of bladder cancer cells
}

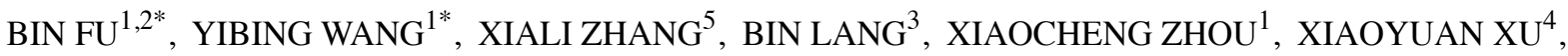 \\ TAO ZENG ${ }^{6}$, WEIPENG LIU ${ }^{1}, \mathrm{XU} \mathrm{ZHANG}^{7}, \mathrm{JU} \mathrm{GUO}^{1}$ and GONGXIAN WANG ${ }^{1,2}$ \\ ${ }^{1}$ Department of Urology, The First Affiliated Hospital of Nanchang University; ${ }^{2}$ Jiangxi Institute of Urology, Jiangxi, \\ Nanchang 330006; ${ }^{3}$ School of Health Sciences, Macao Polytechnic Institute, Macao 999078; \\ ${ }^{4}$ Key Laboratory of System Bio-medicine of Jiangxi Province, Medical College of Jiujiang University, Jiangxi, \\ Jiujiang 332000; ${ }^{5}$ Department of Laboratory Animal Science, Nanchang University; ${ }^{6}$ Jiangxi Provincil People's Hospital, \\ Nanchang 330006; ${ }^{7}$ Department of Urology, Chinese PLA General Hospital, Beijing 100039, P.R. China
}

Received October 13, 2014; Accepted January 5, 2015

DOI: 10.3892/ijo.2015.2837

\begin{abstract}
Immune evasion of cancer cells is mainly due to the impaired transduction of apoptotic signals from immune cells to cancer cells, as well as inhibition of subsequent apoptosis signal cascades within the cancer cells. Over the past few decades, the research has focused more on the impaired transduction of the apoptotic signal from immune cells to cancer cells, rather than inhibition of the intracellular signaling pathways. In this study, miR-221 inhibitor was transfected into bladder cancer cell lines 5637, J82 and T24 to repress the expression of miR-221. As a result, the repression of miR-221 on 553 upregulated modulator of apoptosis (PUMA) was abolished, resulting in increased expression of the pro-apoptotic Bax and reduced expression of the anti-apoptotic Bcl-2, which promotes apoptosis of bladder cancer cells. The expression of MMP-2, MMP-9 and VEGF-C were reduced, resulting in reduced invasiveness and infiltration capability of bladder cancer cells, thereby inhibiting the immune evasion of bladder cancer cells.
\end{abstract}

\section{Introduction}

Bladder cancer is the most common cancer of the urinary system and is showing each year increases in morbidity and mortality $(1,2)$. During tumorigenesis and the cancer development, bladder cancer cells and the host go through three stages: immune surveillance, equilibrium and immune evasion (3). Clinical treatment of bladder cancer is often impeded by immune evasion (4).

Correspondence to: Dr Gongxian Wang, Department of Urology, The First Affiliated Hospital of Nanchang University, Nanchang 330006, P.R. China

E-mail: cuddygongxian@126.com

*Contributed equally

Key words: miR-221, immune escape, bladder cancer
Previous studies have shown that impaired apoptotic signal transduction is one of the important factors promoting immune evasion by cancer cells (5). Accumulating evidence shows the apoptotic signal transduction from immune cells to bladder cancer cells is impaired, resulting in the immune evasion of bladder cancer cells. For instance, antigen B7-H1 binding to PD-1 results in functional inhibition of T cells and B cells, inhibition of body-peculiar cellular and humoral immunity, and induction of apoptosis in specific cytotoxic T lymphocytes (CTL), all of which enable immune evasion of bladder cancer cells and promote the growth of bladder tumors (6). Changes in the apoptosis receptor Fas/FasL also enable evasion of the apoptotic effect from CTL cancer cells (7). Increased expression of TGF- $\beta-1$ leads to the escape of bladder cancer cells from host immune surveillance (8), while deletion or mutation of the MHC-1 gene blocks the apoptotic response from T cells and NK cells (9).

However, immune evasion of cancer cells cannot be completely attributed to the blockage of apoptosis signal transduction from immune cells to cancer cells. It also involves the impaired apoptosis signaling transduction in the cancer cells themselves (9-11). In 2002, microRNA was found to regulate the proliferation and apoptosis of tumor cells (11). Aberrant expression of microRNA in bladder cancer cells was first reported in 2007 (12). Recent studies indicate that there are no binding sites for microRNAs in cell membrane receptor genes or their ligands in cancer cells, many microRNA binding sites are present the downstream signaling pathway effector genes. For example, upregulated miR-221 in malignant bladder tumor inhibits $\mathrm{p} 27^{\mathrm{kip} 1}$ activity, promote proliferation of bladder cancer cells, and inhibits TRAIL-mediated apoptosis signaling $(13,14)$. Given that a microRNA can function on multiple target mRNAs, we hypothesize that miR-221 may silence target mRNAs of other genes and suppress the apoptosis of bladder cancer cells as a result, which would further enable immune evasion by bladder cancer cells. From www. targetscan.org and www.mirbase.org, we found that PUMA, a pro-apoptotic protein that promotes apoptosis might be another target of miR-221. miR-221 and miR-222 have also been found to specifically target PUMA and promote the 
survival of malignant glioma cells (15). Thus, we hypothesize that increased expression of miR-221 in bladder cancer may inhibit the apoptosis of bladder cancer cells through silencing PUMA and maintain the continuous proliferation of bladder cancer cells, leading to their immune evasion.

The major consequences of immune evasion of tumor cells are invasive growth and/or metastasis of tumor cells (16). Previous studies have shown that the degradation and destruction of the extracellular matrix and basement membrane of the tumor surface is the basis for tumor invasion and metastasis $(17,18)$. Matrix metalloproteinases (MMPs) constitute a family of enzymes that are responsible for depredating the extracellular matrix and are closely related with tumor invasion and metastasis. MMP-2 and MMP-9 are two of the most important MMP proteins. MMP-9 degrades and destroys extracellular matrix and basement membrane near the surface of tumor cells, promotes generation of new blood capillaries, tumor growth and migration. MMP-2 degrades types IV, IV, VI and $X$ collagen (19-22). Vascular endothelial growth factor (VEGF) is the most potent known angiogenic factor and plays an important role in the invasive growth and metastasis of many human malignancies (23-25). VEGF can be classified into seven subtypes, namely VEGF-A, VEGF-B, VEGF-C, VEGF-D, VEGF-E, VEGF-F and PIGF, among which VEGF-C is closely related to tumor invasion and metastasis. VEGF-C specifically binds to its cognate receptor on endothelial cells and facilitates mitotic proliferation of endothelial cells, enhances the permeability of blood vessels, changes gene expression in endothelial cells, and thus promotes the synthesis of MMPs (26-28). Therefore in this study, we directly measured the expression of VEGF-C, MMP-2 and MMP-9 in tumor cells to determine the invasion and metastasis state of tumor cells, to indirectly probe if tumor cells are capable of immune evasion.

\section{Materials and methods}

Cell culture. Human bladder cancer cells (T24, 5637 and J82) were obtained from the China Academia Sinica Cell Repository, Shanghai, China. T24 and 5637 cell lines were maintained in RPMI-1640, J82 was maintained in MEM. Both media were supplemented with $10 \%$ heat-inactivated fetal bovine serum without antibiotics at $37^{\circ} \mathrm{C}$ in a humidified incubator with $5 \% \mathrm{CO}_{2}$. All in vitro experiments were performed in triplicate.

Transient transfection. The FAM-modified 2'-OMe-oligonucleotides were chemically synthesized and purified by high-performance liquid chromatography by Invitrogen. The sequence of the 2'-O-me-miR-221 inhibitor is: 5'-GAA ACC CAG CAG ACA AUG UAG CU-3'. The FAM-modified scrambled oligonucleotides are RNA duplexes with the following sequences: 5'-UUC UCC GAA CGU GUC ACG UTT/ACG UGA CAC GUU CGG AGA ATT-3'. FAM was attached to the $5^{\prime}$ end of each oligonucleotide. When cells were grown to 50-60\% confluence, oligonucleotides transfection was performed using the Lipofectamine ${ }^{\mathrm{TM}} 2000$ transfection reagent (Invitrogen, USA) according to the manufacturer's instructions. At $6 \mathrm{~h}$ after transfection, the medium was replaced with fresh medium containing $10 \%$ fetal bovine serum. The experiments consisted of three groups: i) blank (without treatment), ii) negative control (transiently transfected with scrambled oligonucleotide), and iii) transfection of miR-221 inhibitor (transiently transfected with miR-221 inhibitor).

Cell viability assay. Cell viability was tested by 3 -(4,5-dimethylthiazol-2-yl)-2, 5-diphenyltetrazolium bromide (MTT) assay. Briefly, cells were seeded into 96-well plates at a density of 10,000 cells/well in $100 \mu 1$ culture medium and cultured overnight before transfection. Cells received fresh medium at $6 \mathrm{~h}$. After $24 \mathrm{~h}, 20 \mu 1$ MTT $(5 \mathrm{mg} / \mathrm{ml}$ dimethyl thiazolyl diphenyl tetrazolium, Sigma) was added into each test well and incubated for $4 \mathrm{~h}$ in the humidified incubator. Formazan crystals formed by viable cells were dissolved in $150 \mathrm{ml}$ dimethyl sulfoxide (Solarbio) and their absorbance values were measured at $490 \mathrm{~nm}$. Wells without cells (DMSO alone) were used as a background control. The final optical density (OD) was calculated according to the formula: (final optical density = optical density of each group - optical density of DMSO group). Each test was performed daily for three consecutive days and repeated in five wells.

Quantitative real-time PCR. T24, 5637 and J82 cells were transfected for $24 \mathrm{~h}$ as described above. Total RNA was extracted using TRIzol (Invitrogen Life Technologies, Shanghai, China) according to the manufacturer's protocol. RNA quality was determined by running a sample with RNA loading dye (Sigma-Aldrich) on a $1 \%$ agarose gel and inspecting for distinct $18 \mathrm{~S}, 28 \mathrm{~S}$ and total RNA bands which indicate a lack of degradation. The quantity of RNA was determined by A260 measurement.

To evaluate miR-221 expression levels, quantification using the SYBR Green microRNA assay was performed using two-step RT-PCR according to the manufacturer's instructions. In the reverse transcription (RT) step, cDNA was reverse transcribed from the total RNA sample using specific miR-221 primers from the Bulge-Loop ${ }^{\mathrm{TM}}$ hsa-miR-221-5p qRT-PCR Primer Set (RiboBio, Guang Zhou, China) and the Reverse Transcription System (Takara, Dalian, China). In the polymerase chain reaction (PCR) step, $\mathrm{PCR}$ products were amplified from cDNA samples using the Bulge-Loop ${ }^{\mathrm{TM}}$ hsa-miR-221-5p qRT-PCR primer set and using SYBR ${ }^{\circledR}$ Premix Ex Taq $^{\mathrm{TM}}$ II (TliRNase H Plus, Takara) in the ABI PRISM ${ }^{\circledR} 7500$ real-time PCR system (Applied Biosystems, Foster City, CA, USA). The real-time PCR results were normalized against an internal control U6 and relative expression levels were evaluated using the 2- $\Delta \Delta \mathrm{Ct}$ method and then expressed as fold changes.

For qRT-PCR, $1 \mu \mathrm{g}$ total RNA was used in the Reverse Transcription System (Takara) according to the manufacturer's instructions, and PCR was performed in the ABI PRISM ${ }^{\circledR} 7500$ real-time PCR system (Applied Biosystems). The sequences of gene-specific primers are shown in Table I. The expression level of $\beta$-actin was used as internal control. All reactions were performed at least in triplicate.

Invasion assays. The invasion assay was performed in 24-well transwell plates. Type I collagen was coated on the upper chamber to reconstitute the basement membrane. Three groups (transfection of miR-221 inhibitor, negative control and control) of cells $\left(1 \times 10^{5}\right.$ per well) were seeded on the upper chamber, and the lower compartment was filled with RPMI-1640 (T24 
Table I. Oligonucleotide sequences for PCR amplification.

\begin{tabular}{lllll}
\hline Gene & PubMed no. & & $\begin{array}{r}\text { Sequence (5'-3') } \\
\text { Product } \\
\text { size (bp) }\end{array}$ \\
\hline Bax & NM_138764.4 & F: ACCAGGGTGGTTGGGTGAGACT & R: CACCACTGTGACCTGCTCCAGA \\
Bcl-2 & NM_000633.2 & F: CCAGCATGCGGCCTCTGTTTGA & R: TGGGGCAGGCATGTTGACTTCAC \\
PUMA & NM_001127241.1 & F: GCGGGGAGGAGGAACAGT & R: TGTGGCCCCTGGGTAAGG \\
MMP-2 & NM_004994.2 & F: CCTCTCCACTGCCTTCGATA & R: TGGGAGGAGTACAGTCAGCA \\
MMP-9 & NM_001127891.1 & F: CTGCAGTGCCCTGAGGACTA & R: ACTCCTCCCTTTCCTCCAGA \\
VEGF-C & NM_005429.2 & F: GGCTGGCAACATAACAGAGAA & R: CCCCACATCTATACACACCTCC \\
$\beta$-actin & NM_001101.3 & F: CATGTACGTTGCTATCCAGGC & R: CTCCTTAATGTCACGCACGAT \\
\hline
\end{tabular}

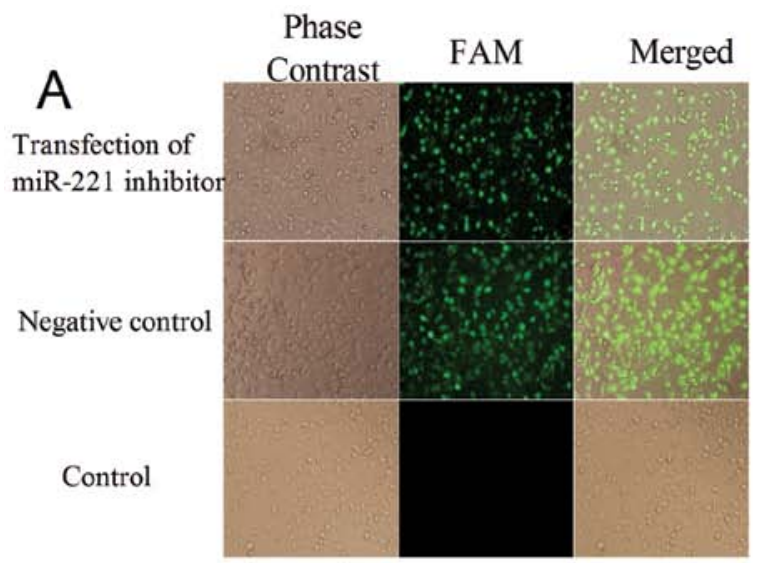

B
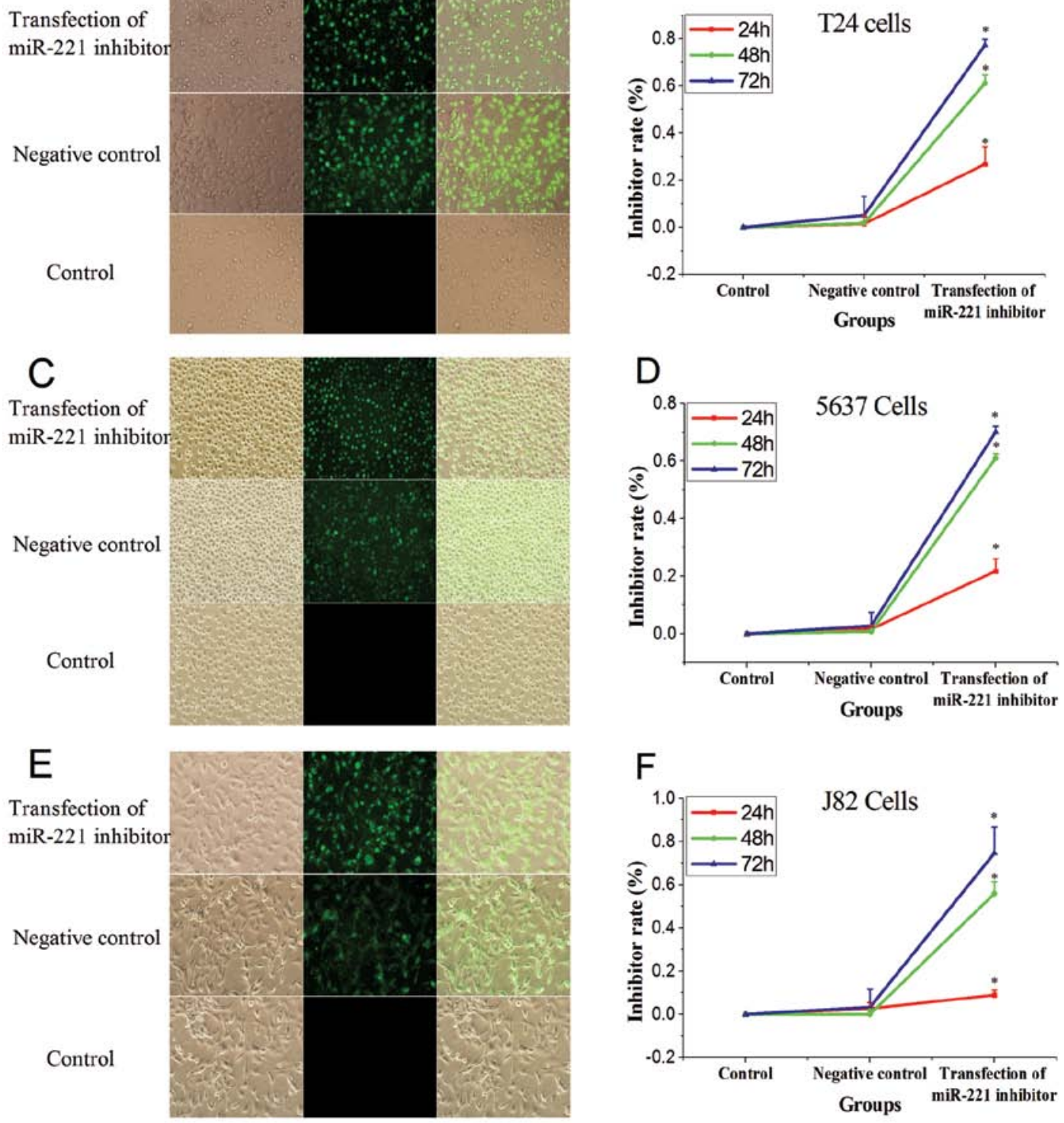

Figure 1. Transfection efficiency and cell viability. (A, C and E) Transfection efficiency of miR-221 inhibitor or scrambled oligonucleotide into T24 (A), 5637 (C) and J82 (E) cells (x200 magnification). (B, D and F) Inhibition rate of three bladder cancer cell lines after transfection for 24,48 and $72 \mathrm{~h}$. ${ }^{*} \mathrm{P}<0.05$ vs. control group.

and 5637 cells) or MEM (J82 cells) containing $10 \%$ fetal calf serum. Cells were cultured for $24 \mathrm{~h}$, fixed in $10 \%$ formaldehyde and stained with crystal violet staining, while the upper chamber cells were gently removed using cotton-tipped swabs. Five microscopic fields (x200) were randomly selected for cell counting. The experiment was repeated three times. 

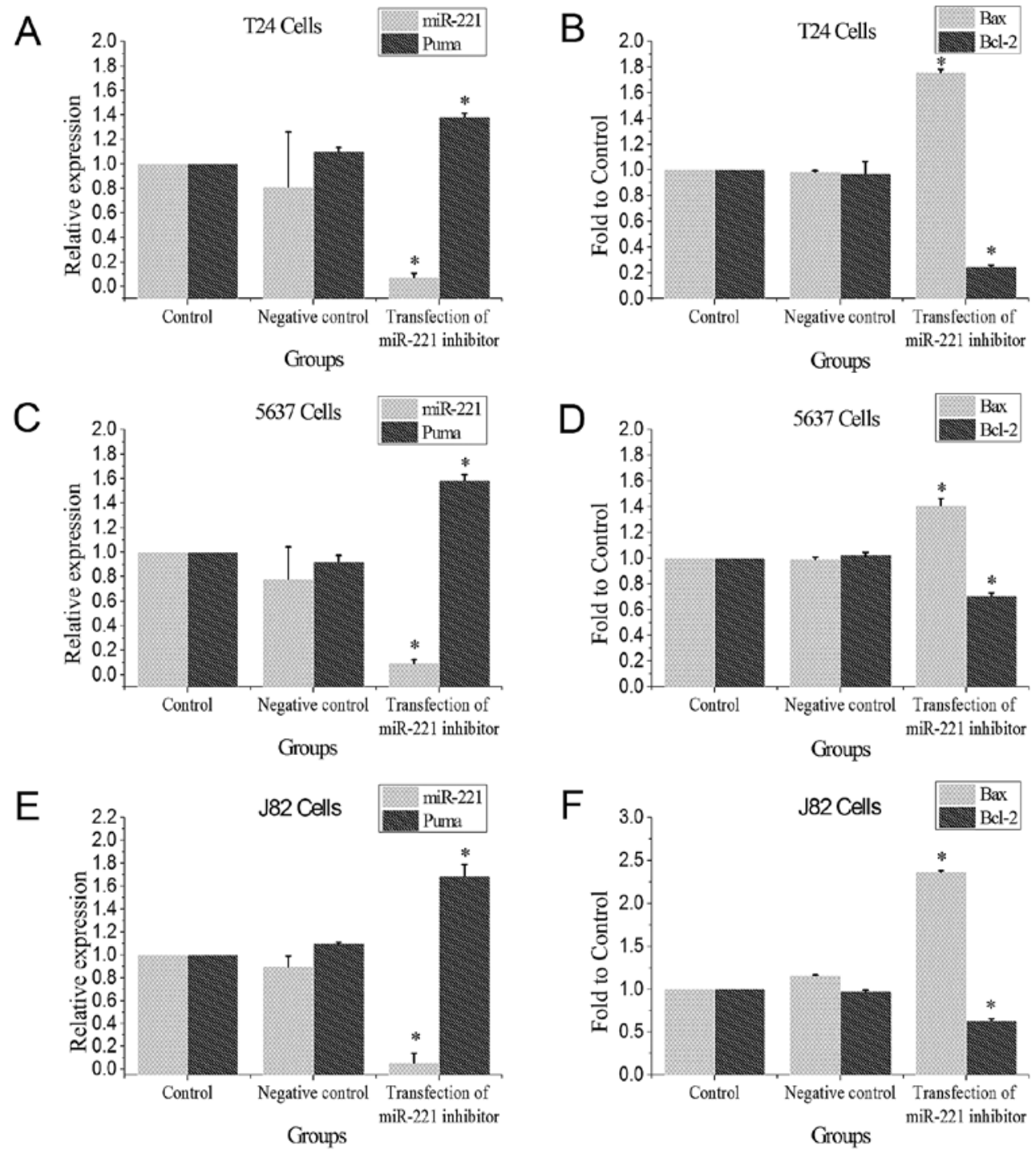

Figure 2. mRNA levels of miR-221, PUMA, Bax and Bcl-2 in T24, 5637 and J82 cells after transfection of miR-221 inhibitor or scrambled oligonucleotide for 48 h. (A) Relative expression of miR-221 and PUMA of T24 cells. (B) Relative expression of Bax and $B c l-2$ of T24 cells. (C) Relative expression of miR-221 and PUMA of 5637 cells. (D) Relative expression of $B a x$ and $B c l-2$ of 5637 cells. (E) Relative expression of miR-221 and PUMA of J82 cells. (F) Relative expression of $B a x$ and $B c l-2$ of $\mathrm{J} 82$ cells, ${ }^{*} \mathrm{P}<0.05$ vs. control group.

Flow cytometry. To evaluate cell apoptosis, singe cell suspensions were prepared for each experimental group, incubated with $5 \mu 1$ FITC-conjugated Annexin $\mathrm{V}$ and $10 \mu \mathrm{l}$ propidium iodide (PI) for $20 \mathrm{~min}$ at room temperature in the dark and were immediately analysed with a FACSCalibur flow cytometer (Becton-Dickinson, Franklin Lakes, NJ, USA). A minimum of 10,000 events were acquired for each sample.

Acridine orangelethidium bromide (AO/EB) staining. Morphological signs of apoptosis were detected by using acridine orange-ethidium bromide (AO/EB) staining. The cells were treated as described above. AO/EB (Sigma) was freshly mixed at $0.01 / 100(\mathrm{v} / \mathrm{v})$ in dark, and one drop of the mixed solution was added to each well for $5 \mathrm{~min}$. The apoptotic cells were then counted under an inverted fluorescence microscope (Eclipse TE300, Nikon, Japan). The death rate (\%) was calculated as the percentage of positively stained cells, number of cells undergoing programmed cell death (PCD x 100/total number of cells. The experiments were repeated twice.
Statistical analysis. All data are presented as the average \pm standard deviation (mean \pm SD). All experiments were repeated three times independently, unless otherwise indicated. Statistical analysis was performed to determine the significance of the difference between groups using ANOVA (with post hoc Turkey's honestly significant difference test). All statistical analyses were performed using SPSS 21.0 software for Windows, $\mathrm{P}<0.05$ is considered as statistically significant.

\section{Results}

miR-221 inhibitor impedes the proliferation of bladder cancer cells. Observation by fluorescence microscopy performed $5 \mathrm{~h}$ after transfection showed that the transfection efficiency for T24, 5637, and $\mathrm{J} 82$ cells were 80,8 and $90 \%$, respectively (Fig. 1). The miR-221 inhibitor was transfected into bladder cancer T24, 5637 and J82 cells. The cell viability was determined at $24 \mathrm{~h}, 48$ and $72 \mathrm{~h}$. Cell proliferation was inhibited in a time-dependent maner, but to varying degrees in the three 


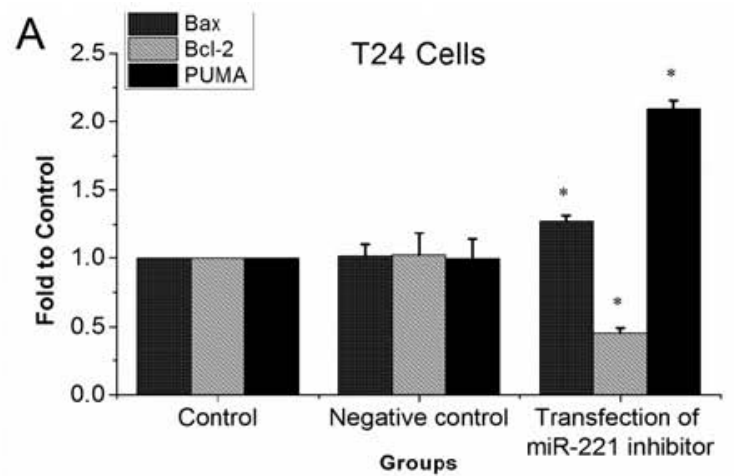

B

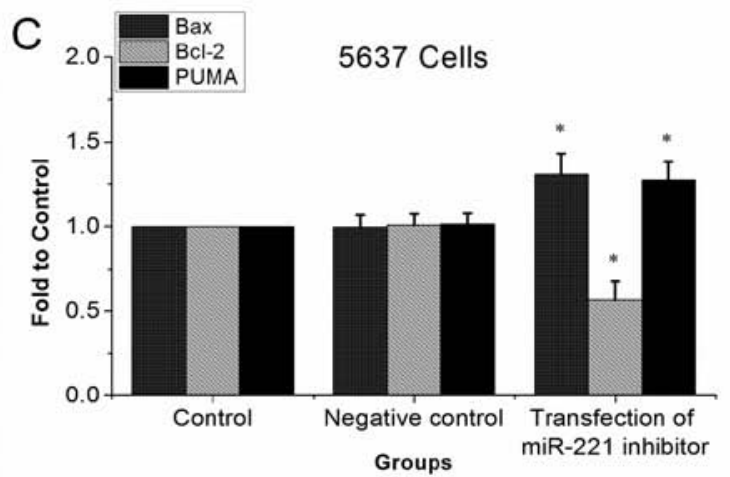

D

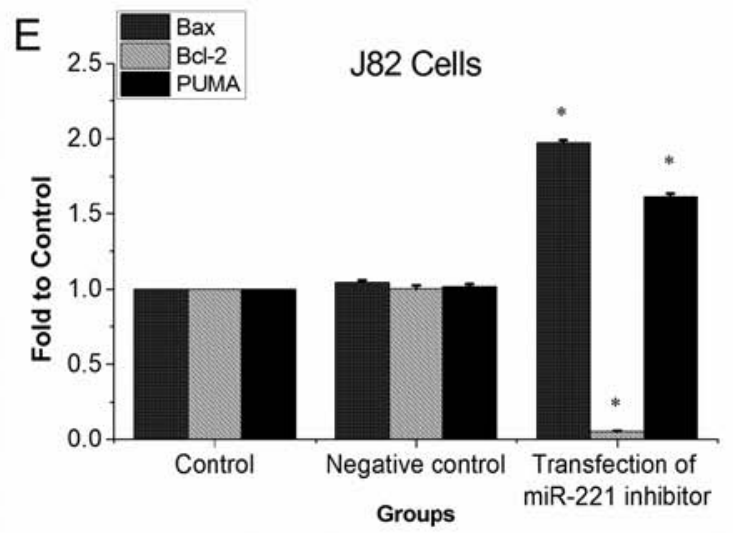

$\mathrm{F}$

Figure 3. Western blot analysis of PUMA, Bax, and Bcl-2 in T24 (A and B), 5637 (C and D) and J82 (E and F) cells after transfection of miR-221 inhibitor or scrambled oligonucleotide for $48 \mathrm{~h}$. ${ }^{*} \mathrm{P}<0.05$ vs. control group.

tested lines. In addition, the rate of inhibition of cell proliferation increased with increasing time $(\mathrm{P}<0.05$, vs. control group, Fig. 1D).

Transfection of miR-221 inhibitor reduces miR-221 expression. The T24, 5637 and J82 bladder cancer cells were transfected with miR-221 inhibitor for $48 \mathrm{~h}$, miR-221 expression levels were determined by qRT-PCR. Transfection of miR-221 significantly reduced miR-221 expression when compared to the control group and the negative control group $(\mathrm{P}<0.05$, Fig. 2$)$.

miR-221 inhibitor induces mRNAs of PUMA and Bax, and reduces Bcl-2 $m R N A$. Results from qRT-PCR showed that after miR-221 expression was inhibited in the three bladder cancer cell lines, PUMA and Bax mRNA levels were significantly induced, while mRNA of the anti-apoptotic Bcl-2 was
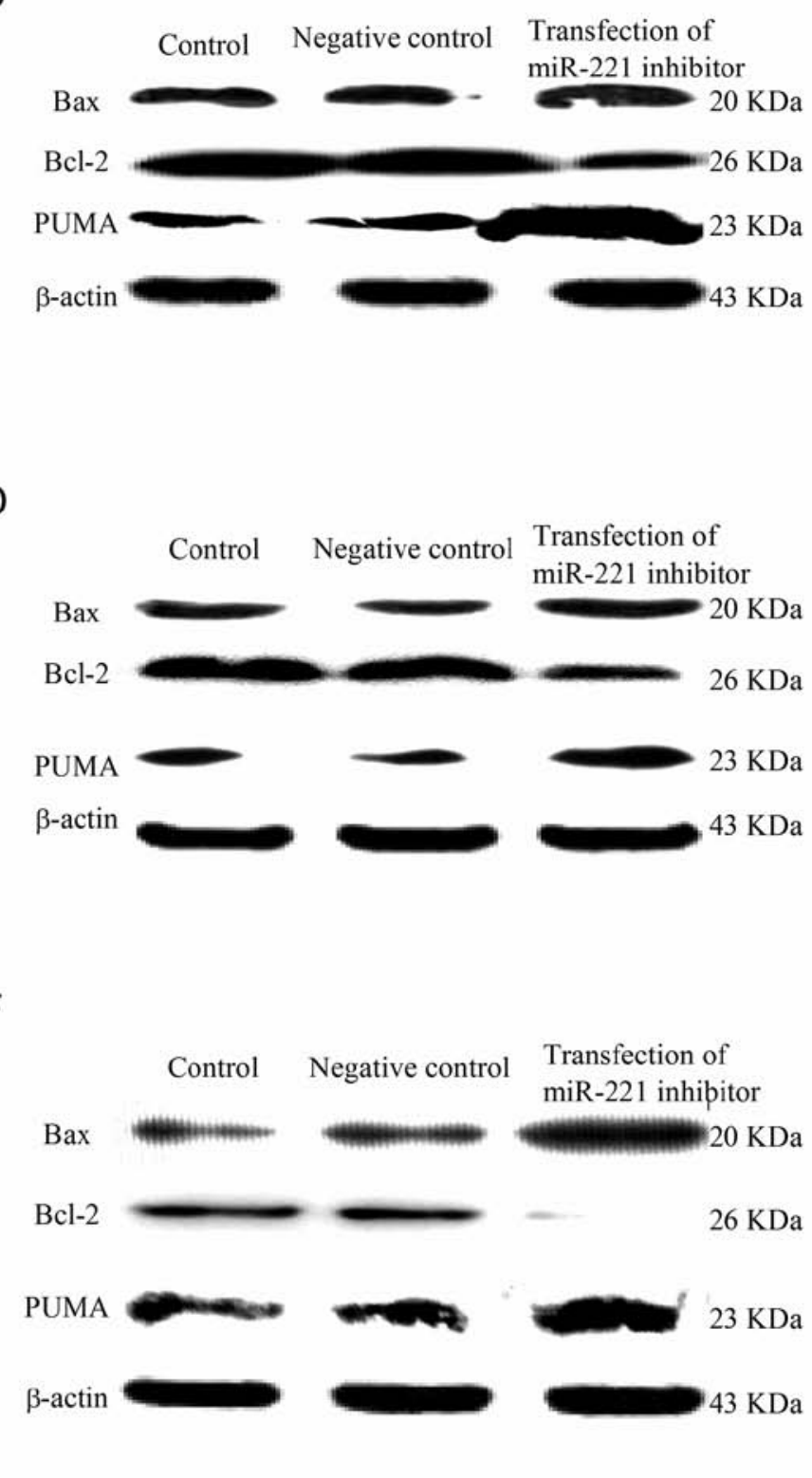
A a
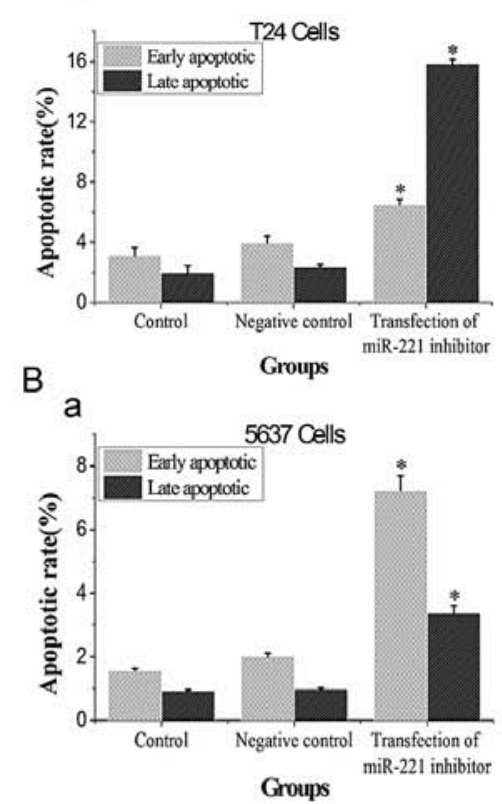

C a

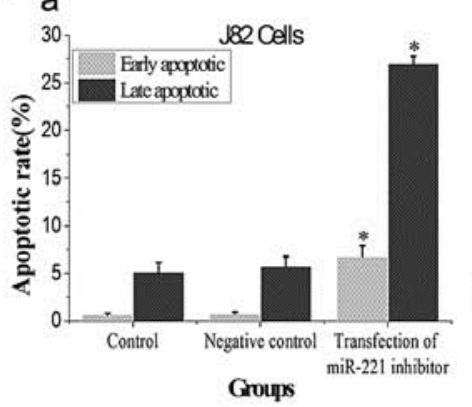

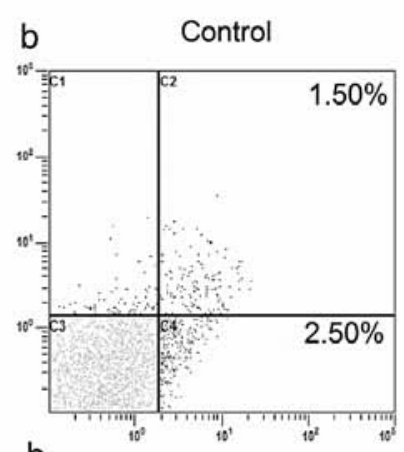

b

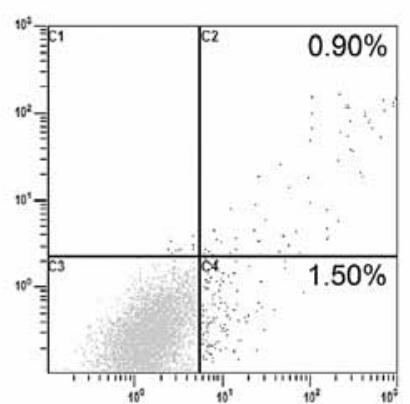

b

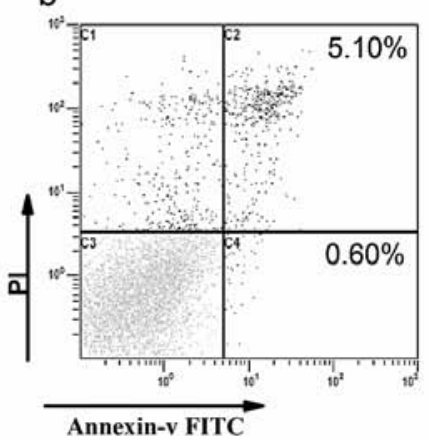

c Negative control

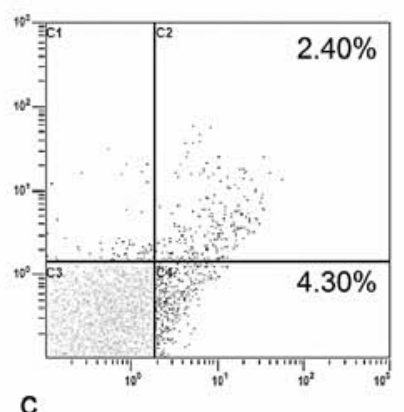

c

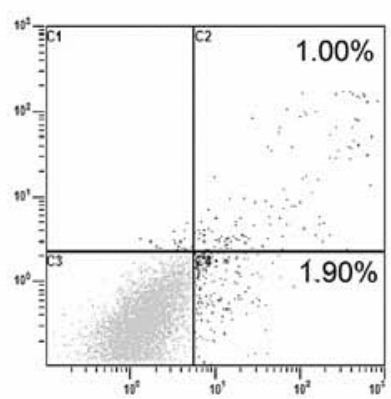

C

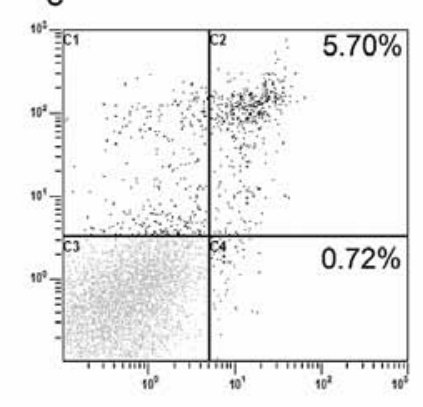

Transfection of d miR-221 inhibitor
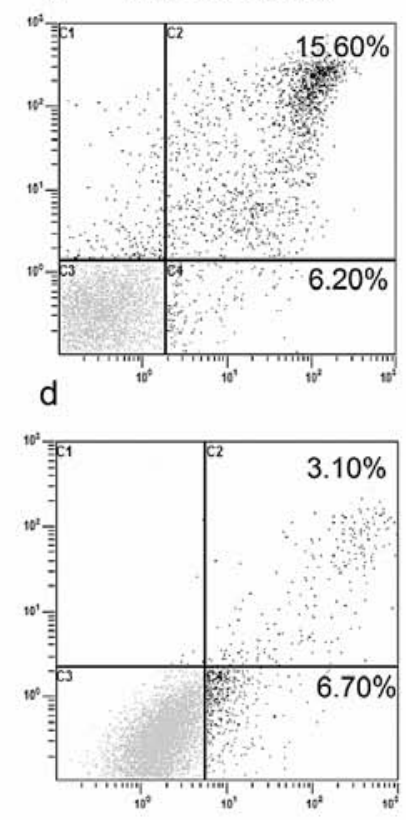

d

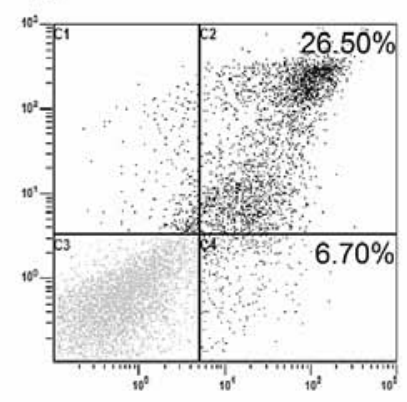

Figure 4. Flow cytometry analysis of apoptosis rate in T24 (A), 5637 (B) and J82 (C) cells after transfection of miR-221 inhibitor or scrambled oligonucleotide for $48 \mathrm{~h}$. ${ }^{*} \mathrm{P}<0.05$ vs. control group.

significantly higher than the damage in control groups in all three cell lines (Fig. 5).

miR-221 inhibitor reduces $m R N A$ levels of $M M P-9, M M P-2$, and $V E G F-C$. Results from qRT-PCR showed that in T24, 5637 and J82 cells MMP-9, MMP-2, and VEGF-C mRNA levels were significantly lower in miR-221 inhibitor transfected groups than in control groups $(\mathrm{P}<0.05$, Fig. 6$)$.

miR-221 inhibitor reduces MMP-9, MMP-2, and VEGF-C protein expression. Western blotting showed that in T24, 5637, and J82 cells, MMP-9, MMP-2, and VEGF-C protein levels were significantly lower in miR-221 inhibitor transfected groups than in the control groups $(\mathrm{P}<0.05$, Fig. 7).

miR-221 inhibitor reduces the invasiveness of bladder cancer cells. Transwell assays showed that in T24, 5637 and J82 cells, the invasiveness of bladder cancer cells was significantly reduced in miR-221 inhibitor transfected groups than in the control groups $(\mathrm{P}<0.05$, Fig. 8). There was no significant difference in invasive capability between the control groups and negative control groups.

\section{Discussion}

Interactions between the immune system and tumor cells play a very important role in tumorigenesis. Failure of the immune system to recognize or kill cancer cells leads to tumor occurrence and development. Immune killing of tumor cells involves the transmission of apoptotic signals from immune cells to tumor cells, as well as the subsequent transduction of the apoptotic signal in tumor cells. However, most of the research on immune evasion of tumor cells focuses on the ability of cancer cells to block the apoptotic signal as it is transmitted from immune cells to tumor cells (29). In fact, transmission of the apoptotic signal from immune cells to tumor cells is actually not blocked completely, which means that tumor cells do receive attenuated apoptotic signals from immune cells (9-11). Therefore, abnormal intracellular transduction of apoptotic signals in tumor cells may be another important factor for immune evasion.

Apoptosis is a process of programmed autonomous cell death. It is induced by a variety of factors inside and outside the body and is controlled by strict and complex regulation of signaling networks (30-32). Currently, three pathways 


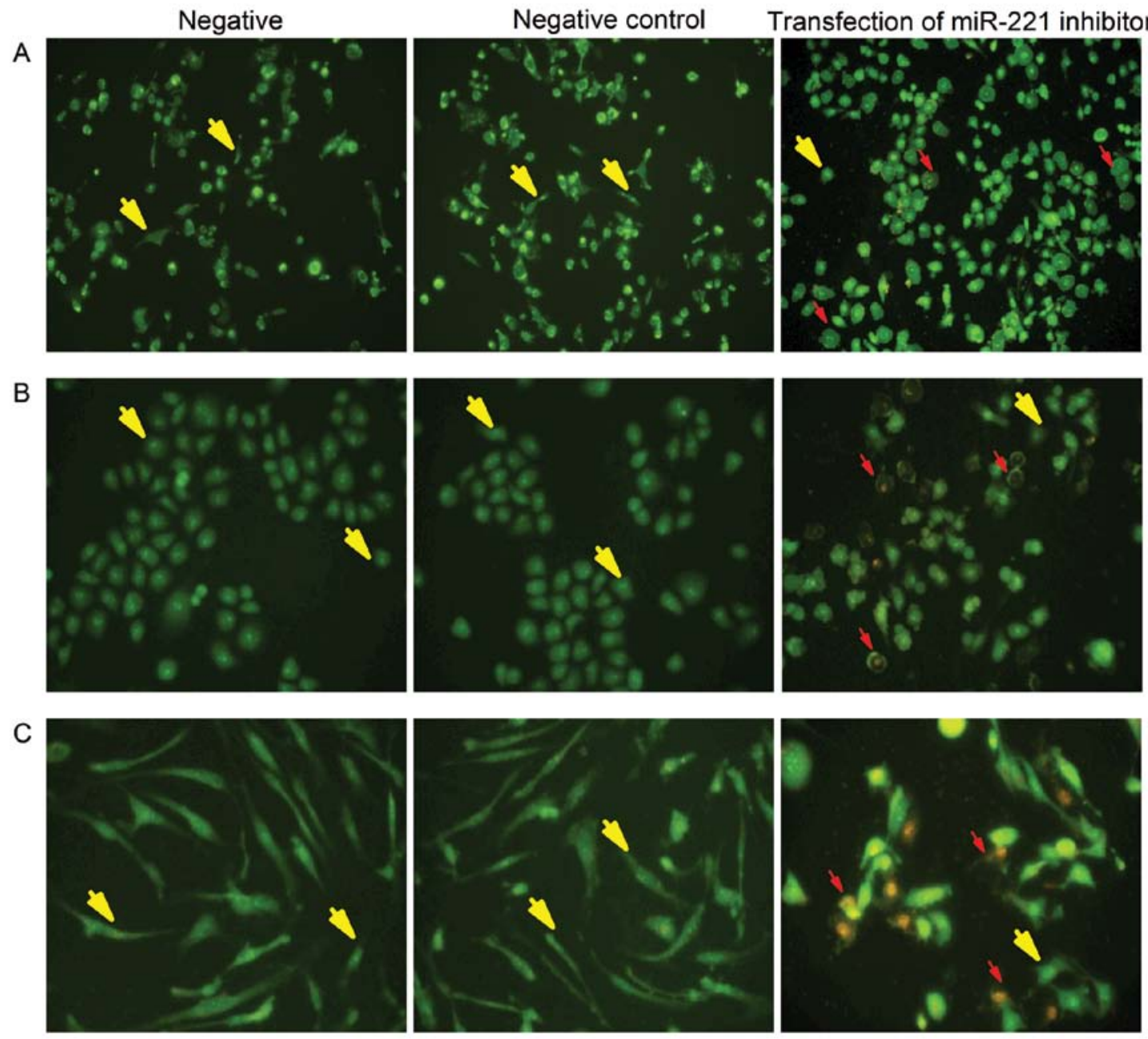

Figure 5. AO-EB staining T24 (A), 5637 (B) and J82 (C) cells. Red arrows indicate apoptotic cells and yellow arrows indicate normal cells.
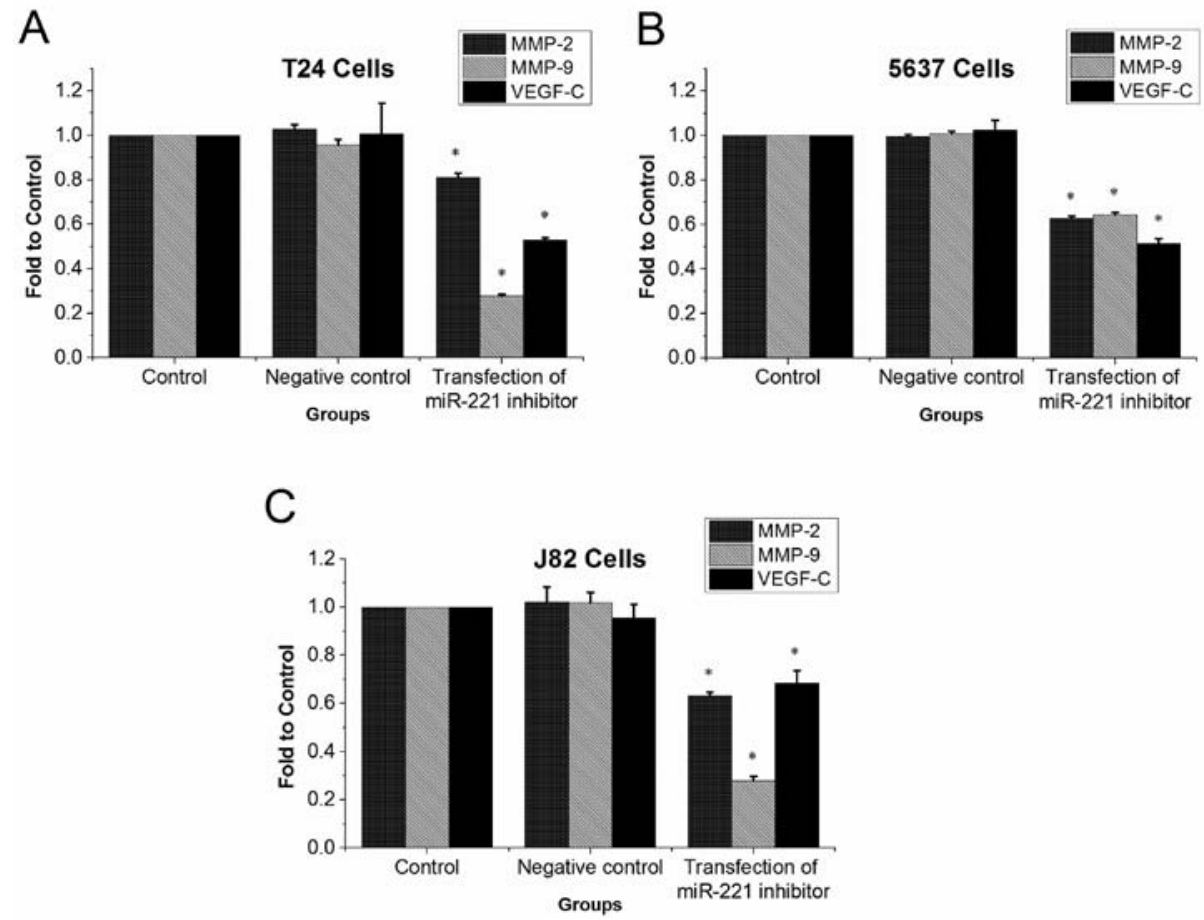

Figure 6. qRT-PCR analysis of MMP-2, MMP-9 and VEGF-C in each group of T24 (A), 5637 (B) and J82 (C) cells after transfection of miR-221 inhibitor or scrambled oligonucleotide for $48 \mathrm{~h} .{ }^{*} \mathrm{P}<0.05$ vs. control group. 

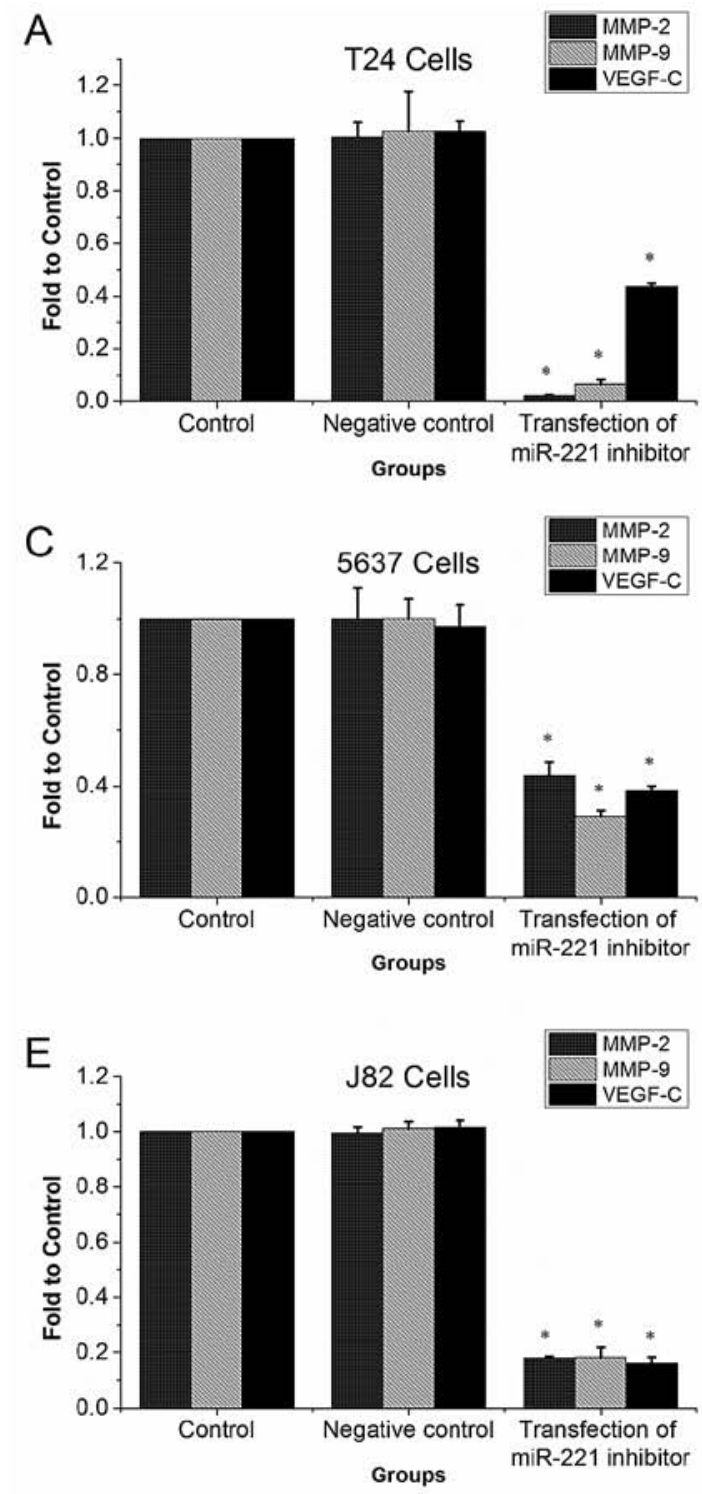

B

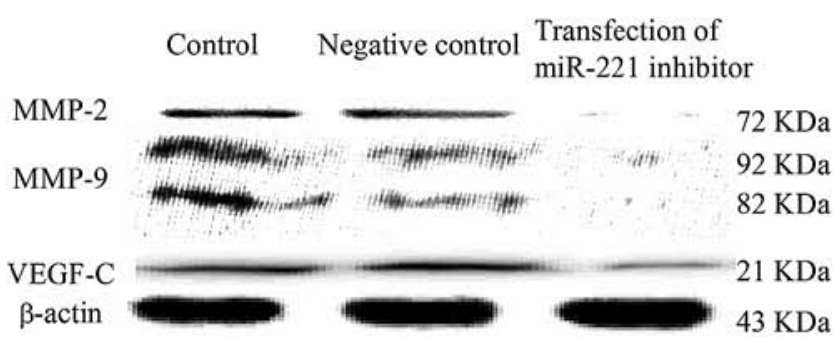

D

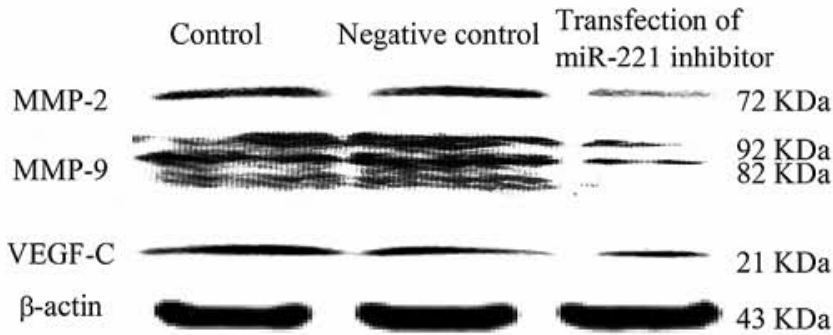

$\mathrm{F}$

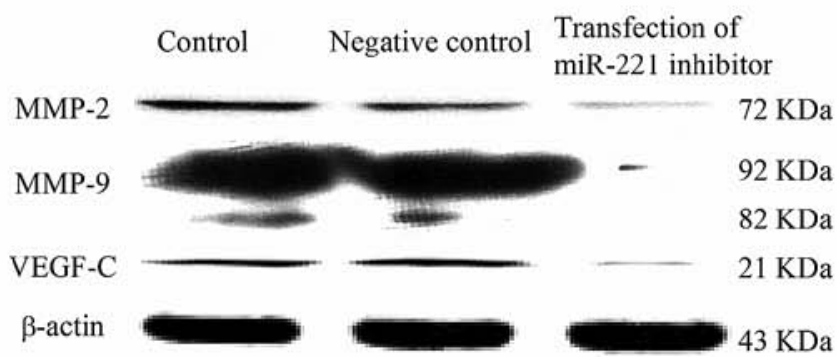

Figure 7. Western blot analysis of MMP-2, MMP-9 and VEGF-C in T24 (A and B), 5637 (C and D), and J82 (E and F) cells after transfection of miR-221 inhibitor or scrambled oligonucleotide for $48 \mathrm{~h}$. ${ }^{*} \mathrm{P}<0.05$ vs. control group.

of cell apoptosis have been characterized. The first is the intrinsic apoptotic pathway, namely the mitochondrial apoptotic pathway, in which the intracellular signal transduction involves the interaction of pro-apoptotic factors and the antiapoptotic Bcl-2 protein family. The second apoptosis pathway is the endoplasmic reticulum signaling pathway, which does not yet have a clear mechanism. The third apoptosis pathway is the extrinsic apoptosis pathway, also termed as dead receptor pathway, which induces apoptosis by activating the corresponding ligands and initiating the death receptors on the cell surfaces (33-38). The three pathways are interrelated. For instance, the extrinsic apoptotic pathway can activate the mitochondrial apoptotic pathway by activation of Bid (39).

PUMA was first reported by Nakano in 2001 (74) as a member of the BH3-only subfamily in the Bcl-2 family. It is a pro-apoptosis factor. The pro-apoptosis function of PUMA mainly depends on its $\mathrm{BH} 3$ domain and the orderliness and integrity of the 43 amino acid residues at its C-terminus (34,39-41). Previous studies have shown that the pro-apoptotic mechanism of PUMA acts through various mechanisms, ultimately causing depolarization of the mitochondrial membrane potential and initiating the mitochondrial apoptosis pathway. This results in the release of cytochrome $c$ and Smac/ DIABLO into the cytoplasm and the activation of apoptosis $(15,42-44)$. However, the expression of PUMA is regulated by transcription factors (p53, c-Myc and FoxO3a) as well as posttranscriptional regulation (miR-221/miR-222) (44-48).

It has been reported that miR-221 expression is upregulated in bladder cancer tissues compared to adjacent bladder tissues and that miR-221 can specifically target the $3^{\prime}$ non-coding region of the mature PUMA mRNA and silence PUMA expression $(12,44,49)$. In this study, miR-221 inhibitor (modified by 2 ' O-methylation and FAM) and a negative control sequence were transfected into bladder cancer cells. After transfection with miR-221 inhibitor for 24,48 and $72 \mathrm{~h}$, cell viability was measured using the MTT assay. Results indicated that miR-221 inhibitor significantly impedes the proliferation of bladder cancer cells. Furthermore, the inhibition of prolifera- 
A

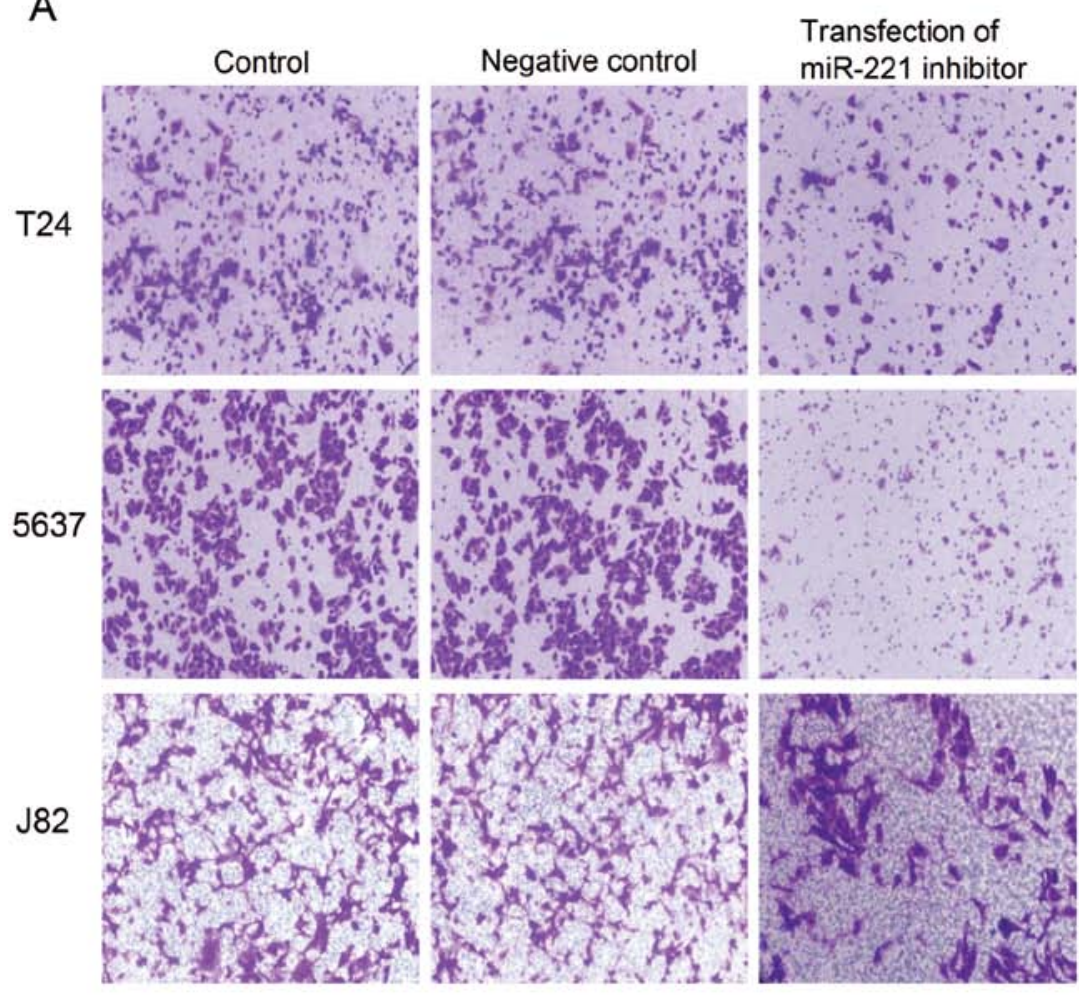

B

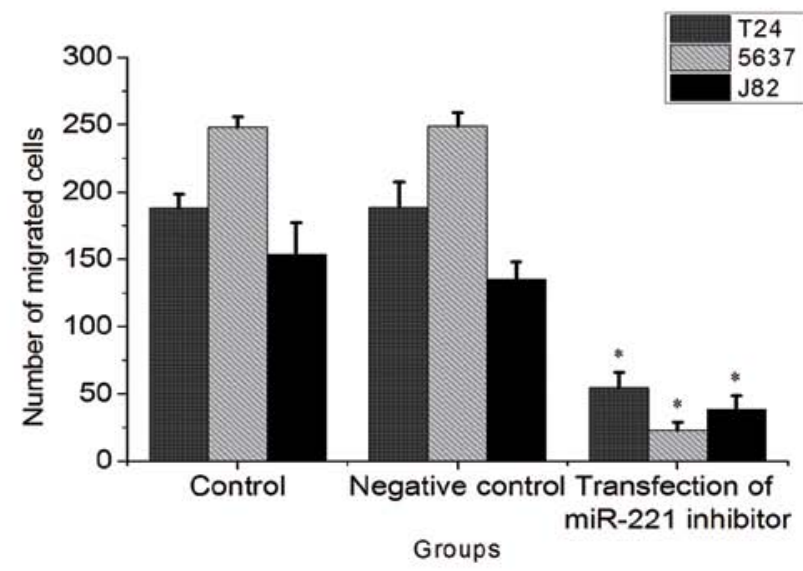

Figure 8. Downregulation of miR-221 suppresses bladder cancer cell invasion. (A) Representative image of six Transwell migration experiments is shown for T24, 5637 and J82 cells (x200). (B) Columns, mean ( $\mathrm{n}=3$ ); bars, SD. " $\mathrm{P}<0.05$ vs. control group.

tion is time-dependent, indicating that a decrease in miR-221 suppresses cell proliferation. Floating cell debris after our 72-h transfection made it more difficult to meet the requirements of subsequent experiments, so we chose to transfect miR-221 inhibitor for $48 \mathrm{~h}$ in subsequent experiments. Taking our qRT-PCR and western blotting results together, we have shown that, $48 \mathrm{~h}$ after transfection of miR-221 inhibitor, miR-221 mRNA levels were significantly inhibited, resulting in an increase in PUMA and Bax mRNA and protein, but a decrease in Bcl-2 mRNA and protein. Flow cytometry and AO-EB staining assays confirmed that miR-221 inhibition promotes apoptosis in bladder cancer cells. Collectively, the overexpression of endogenous miR-221 is an important factor for the inhibition of apoptosis in bladder cancer cells.

Tumor cells capable of immune evasion are not only able to resist apoptosis, but can also release immunosuppressive factors into the extracellular environment by autocrine or paracrine secretion, which results in deep immunosuppressive regions formed locally in tumor cells. The formation of these regions is one of the important mechanisms of tumor cell immune evasion. Among these immunosuppressive factors, VEGF and MMP play important roles in tumor invasion and metastasis.

There are seven VEGF isoforms, namely VEGF-A, VEGF-B, VEGF-C, VEGF-D, VEGF-E, VEGF-F and PIGF (50). VEGF-C plays an important role in the regulation of tumor metastasis and infiltration. Previous studies have shown that VEGF-C is a protein precursor that must be activated by converting enzyme (proprotein convertases, PC) 5 and 7 (51,52). The associated receptors of VEGF-C include VEGFR-2, VEGFR-3 and Nrp-2, among which VEGFR-3 is the receptor that promotes lymphangiogenesis and tumor 
cell migration, invasion and metastasis. Study of Nrp-2 has suggested that Nrp-2 only plays a regulatory role and is not a necessary receptor during lymphangiogenesis (53-57). In human tumors, abnormal VEGFR-3 expression has been found in gastric cancer (58), lung cancer (59), colorectal cancer $(60,61)$, head and neck cancer (62), bladder cancer (63), and breast cancer (64). Based on these previous studies, we confirmed that VEGF-C overexpression in tumor cells is the premise and one of the early events of tumor cell micrometastasis into the lymph node. Studies on immune evasion have confirmed that VEGF-C is a potent immunosuppressive factor, which not only impedes immune cells from recognizing tumor cells, but can also destroy the biological functions of immune cells (65). In this study, after transfecting miR-221 inhibitor into T24, 5637 and J82 bladder cancer cells, VEGF-C mRNA and protein expression levels decreased significantly. It remains to be further studied whether this phenomenon is due to the upregulation of pro-apoptotic genes PUMA and Bax, the downregulation of anti-apoptotic Bcl-2, or other mechanisms, but it is clear that miR-221 did not directly regulate the effects of VEGF-C. Taken together, decreased miR-221 in bladder cancer reduces the effects of VEGF-C in promoting the formation of microlymphatic vessels and capillary vessels at tumor sites, as well as the ability of VEGF-C to inhibit immune cell activity.

There are many members in the family of MMPs, among which MMP-2 and MMP-9 are closely associated with tumor invasion and development. Their main mechanism of action include: i) MMP-2 and MMP-9 degrade the extracellular matrix and basement membrane and destroy cell structure. In addition, MMP-2 has the potential capability to activate extracellular matrix structural proteins and plays an important role in the chemotaxis of inflammatory cells as well as the spontaneous stimulation of tumor cells for migration and invasion; ii) MMPs promote tumor angiogenesis. As blood vessel formation is a prerequisite for the tumor cell growth, metastasis and invasion, MMP-2 promotes angiogenesis after interacting with their corresponding substrates. At the initial stage of tumor angiogenesis in tumor nodules, MMP-2 secretion is essential for tumor cells (66-70). In this study, after transfecting miR-221 inhibitor into bladder cancer T24, 5637 and $\mathrm{J} 82$ cells for $48 \mathrm{~h}$, we found that both the mRNA and protein levels of MMP-2 and MMP-9 decreased. Although we only detected total MMP-2 and MMP-9 protein, rather than their phosphorylated isoforms which are the activated forms, our Transwell results indicate that cancer cell invasiveness was significantly decreased after reducing miR-221. Furthermore, MMP-2 and MMP-9 are closely related to tumor cell invasion (71-73). Therefore, the overexpression of MMP-2 and MMP-9 in bladder cancer is likely an important factor for the invasion and metastasis of bladder cancer cells.

In conclusion, this study showed that the overexpression of miR-221 in bladder cancer cells inhibits the expression of the pro-apoptotic gene PUMA, thereby inhibiting the transduction of apoptotic signals. Meanwhile, the downregulation of miR-221 in bladder cancer cells reduced the expression of VEGF-C, MMP-2 and MMP-9, resulting in reduced invasion of bladder cancer cells. Therefore, miR-221-induced PUMA silencing is a key factor for the immune evasion of bladder cancer.

\section{Acknowledgements}

This study was supported by the National Natural Science Foundation of China (grant no. 81160272) and the Natural Science Foundation of Jiangxi (grant no. 800GZY0039) and the Jiangxi Province Science Foundation for Youths (grant no. 2010JX02761) and The Science and Technology Development Fund of Macao Special Administrative Region (grant no. 064/2012/A).

\section{References}

1. Abedinpour P, Baron VT, Welsh J, et al: Regression of prostate tumors upon combination of hormone ablation therapy and celecoxib in vivo. Prostate 71: 813-823, 2011.

2. Ahmad A, Aboukameel A, Kong DJ, et al: Phosphoglucose isomerase/autocrine motility factor mediates epithelial-mesenchymal transition regulated by miR-200 in breast cancer cells. Cancer Res 71: 3400-3409, 2011.

3. Akkoc A, Inan S and Sonmez G: Matrix metalloproteinase (MMP-2 and MMP-9) and steroid receptor expressions in feline mammary tumors. Biotech Histochem 87: 312-319, 2012.

4. Amente S, Zhang J, Lavadera ML, et al: Myc and PI3K/AKT signaling cooperatively repress FOXO3a-dependent PUMA and GADD45a gene expression. Nucleic Acids Res 39: 9498-9507, 2011.

5. Asirvatham AJ, Gregorie CJ, Hu Z, et al: MicroRNA targets in immune genes and the Dicer/Argonaute and ARE machinery components. Mol Immunol 45: 1995-2006, 2008.

6. Bean GR, Ganesan YT, Dong YY, et al: PUMA and BIM are required for oncogene inactivation-induced apoptosis. Sci Signal 6: ra20, 2013. doi: 10.1126/scisignal.2003483.

7. Campone M, Noel B, Couriaud C, et al: c-Myc dependent expression of pro-apoptotic Bim renders HER2-overexpressing breast cancer cells dependent on anti-apoptotic Mcl-1. Mol Cancer 10: 110, 2011.

8. Catto JW, Alcaraz A, Bjartell AS, et al: MicroRNA in prostate, bladder, and kidney cancer: a systematic review. Eur Urol 59: 671-681, 2011.

9. Chang LY, Lin YC, Mahalingam J, et al: Tumor-derived chemokine CCL5 enhances TGF-beta-mediated killing of CD8(+) T cells in colon cancer by T-regulatory cells. Cancer Res 72: 1092-1102, 2012.

10. Chen L, Zhang J, Han L, et al: Downregulation of miR-221/222 sensitizes glioma cells to temozolomide by regulating apoptosis independently of p53 status. Oncol Rep 27: 854-860, 2012.

11. Chopin D, Barei-Moniri R, Maille P, et al: Human urinary bladder transitional cell carcinomas acquire the functional Fas ligand during tumor progression. Am J Pathol 162: 1139-1149, 2003.

12. Di Martino MT, Gulla A, Cantafio ME, et al: In vitro and in vivo anti-tumor activity of miR-221/222 inhibitors in multiple myeloma. Oncotarget 4: 242-255, 2013.

13. Eissa S, Badr S, Elhamid SA, et al: The value of combined use of survivin mRNA and matrix metalloproteinase 2 and 9 for bladder cancer detection in voided urine. Dis Markers 34: 57-62, 2013.

14. Eissa S, Shabayek MI, Ismail MF, et al: Diagnostic evaluation of apoptosis inhibitory gene and tissue inhibitor matrix metalloproteinase-2 in patients with bladder cancer. IUBMB Life 62: 394-399, 2010.

15. Errami Y, Naura AS, Kim H, et al: Apoptotic DNA fragmentation may be a cooperative activity between caspase-activated deoxyribonuclease and the poly(ADP-ribose) polymerase-regulated DNAS1L3, an endoplasmic reticulum-localized endonuclease that translocates to the nucleus during apoptosis. J Biol Chem 288: 3460-3468, 2013.

16. Follis AV, Chipuk JE, Fisher JC, et al: PUMA binding induces partial unfolding within BCL-xL to disrupt p53 binding and promote apoptosis. Nat Chem Biol 9: 163-168, 2013.

17. Foster RR, Satchell SC, Seckley J, et al: VEGF-C promotes survival in podocytes. Am J Physiol Renal Physiol 291: F196-F207, 2006.

18. Garcia-Lora A, Algarra I and Garrido F: MHC class I antigens, immune surveillance, and tumor immune escape. J Cell Physiol 195: 346-355, 2003. 
19. Gottardo F, Liu CG, Ferracin M, et al: Micro-RNA profiling in kidney and bladder cancers. Urol Oncol 25: 387-392, 2007.

20. Holoch PA and Griffith TS: TNF-related apoptosis-inducing ligand (TRAIL): a new path to anti-cancer therapies. Eur J Pharmacol 625: 63-72, 2009.

21. Igney FH and Krammer PH: Immune escape of tumors: apoptosis resistance and tumor counterattack. J Leukoc Biol 71: 907-920, 2002.

22. Inman BA, Sebo TJ, Frigola X, et al: PD-L1 (B7-H1) expression by urothelial carcinoma of the bladder and BCG-induced granulomata: associations with localized stage progression. Cancer 109: 1499-1505, 2007.

23. Jayasinghe C, Simiantonaki N, Michel-Schmidt R, et al: Endothelial VEGFR-3 expression in colorectal carcinomas is associated with hematogenous metastasis. Oncol Rep 22: 1093-1100, 2009.

24. Jayasooriya RG, Choi YH, Moon SK, et al: Methanol extract of Hydroclathrus clathratus suppresses matrix metalloproteinase- 9 in T24 bladder carcinoma cells by suppressing the NF-kappaB and MAPK pathways. Oncol Rep 27: 541-546, 2012.

25. Jemal A, Bray F, Center MM, et al: Global cancer statistics. CA Cancer J Clin 61: 69-90, 2011.

26. Jin X, Xiao LJ, Zhang XS, et al: Apotosis in ovary. Front Biosci (Schol Ed) 3: 680-697, 2011.

27. Kajiya K, Sawane M, Huggenberger R, et al: Activation of the VEGFR-3 pathway by VEGF-C attenuates UVB-induced edema formation and skin inflammation by promoting lymphangiogenesis. J Invest Dermatol 129: 1292-1298, 2009.

28. Khong HT and Restifo NP: Natural selection of tumor variants in the generation of 'tumor escape' phenotypes. Nat Immunol 3 999-1005, 2002.

29. Krebs R, Tikkanen JM, Ropponen JO, et al: VEGF-C/VEGFR-3 signaling regulates inflammatory response in development of obliterative airway disease. J Heart Lung Transpl 30: S118, 2011.

30. Langers AMJ, Verspaget HW, Hawinkels LJAC, et al: MMP-2 and MMP-9 in normal mucosa are independently associated with outcome of colorectal cancer patients. Br J Cancer 106: 1495-1498, 2012

31. Li XQ, Dang XG and Sun XB: Expression of survivin and VEGF-C in breast cancer tissue and its relation to lymphatic metastasis. Eur J Gynaecol Oncol 33: 178-182, 2012.

32. Li Y, Yang K, Mao Q, et al: Inhibition of TGF-beta receptor I by siRNA suppresses the motility and invasiveness of T24 bladder cancer cells via modulation of integrins and matrix metalloproteinase. Int Urol Nephrol 42: 315-323, 2010.

33. Lund AW, Duraes FV, Hirosue S, et al: VEGF-C promotes immune tolerance in B16 melanomas and cross-presentation of tumor antigen by lymph node lymphatics. Cell Rep 1: 191-199, 2012.

34. Martins SF, Garcia EA, Luz MA, et al: Clinicopathological correlation and prognostic significance of VEGF-A, VEGF-C, VEGFR-2 and VEGFR-3 expression in colorectal cancer. Cancer Genomics Proteomics 10: 55-67, 2013.

35. Min Y, Ghose S, Boelte K, et al: C/EBP-delta regulates VEGF-C autocrine signaling in lymphangiogenesis and metastasis of lung cancer through HIF-1 alpha. Oncogene 30: 4901-4909, 2011.

36. Neal MD, Sodhi CP, Jia H, et al: The P53 upregulated modulator of apoptosis (Puma) regulates Tlr4-mediated enterocyte apopotosis in the pathogenesis of necrotizing enterocolitis. Shock 35 60-60, 2011.

37. Newton MR, Askeland EJ, Andresen ED, et al: Antiinterleukin-10R1 monoclonal antibody in combination with BCG is protective against bladder cancer metastasis in a murine orthotopic tumor model and demonstrates systemic specific antitumor immunity. Clin Exp Immunol 177: 261-268, 2014.

38. Niederkorn JY: Immune escape mechanisms of intraocular tumors. Prog Retin Eye Res 28: 329-347, 2009.

39. Okada A: Roles of matrix metalloproteinases and tissue inhibitor of metalloproteinase (TIMP) in cancer invasion and metastasis. Gan To Kagaku Ryoho 26: 2247-2252, 1999.

40. Okada R, Nagaosa K, Kuraishi T, et al: Apoptosis-dependent externalization and involvement in apoptotic cell clearance of DmCaBP1, an endoplasmic reticulum protein of Drosophila. J Biol Chem 287: 3138-3146, 2012.

41. Olofsson B, Jeltsch M, Eriksson U, et al: Current biology of VEGF-B and VEGF-C. Curr Opin Biotech 10: 528-535, 1999.

42. Piazzolla G, Nuzzaci M, Vitti A, et al: Apoptotic effects of a chimeric plant virus carrying a mimotope of the hepatitis $C$ virus hypervariable region 1: role of caspases and endoplasmic reticulum-stress. J Clin Immunol 32: 866-876, 2012.
43. Planaguma L, Liljestrom M, Alameda F, et al: Matrix metalloproteinase-2 and matrix metalloproteinase-9 codistribute with transcription factors RUNX1/AML1 and ETV5/ERM at the invasive front of endometrial and ovarian carcinoma. Hum Pathol 42: 57-67, 2011.

44. Poyet C, Banzola I, Linto T, et al: Bladder cancer microenvironment influences maturation signature in lymphatic endothelial cells (LECs) by VEGF-C. Eur Urol (Suppl) 11: E906-U905, 2012.

45. Rabinovich GA, Gabrilovich D and Sotomayor EM: Immunosuppressive strategies that are mediated by tumor cells. Annu Rev Immunol 25: 267-296, 2007.

46. Saharinen P, Eklund L, Pulkki K, et al: VEGF and angiopoietin signaling in tumor angiogenesis and metastasis. Trends Mol Med 17: 347-362, 2011.

47. Sato H, Takino T and Miyamori H: Roles of membrane-type matrix metalloproteinase-1 in tumor invasion and metastasis. Cancer Sci 96: 212-217, 2005.

48. Seiler R, Thalmann GN and Fleischmann A: MMP-2 and MMP-9 in lymph-node-positive bladder cancer. J Clin Pathol 64: 1078-1082, 2011

49. Senger DR, Van de Water L, Brown LF, et al: Vascular permeability factor (VPF, VEGF) in tumor biology. Cancer Metastasis Rev 12: 303-324, 1993.

50. Siddle H, Kreiss A, Tovab C, et al: Immune escape strategies of a contagious cancer, devil facial tumour disease. Mol Immunol 51: 30, 2012.

51. Siriwardena BSMS, Kudo Y, Ogawa I, et al: VEGF-C is associated with lymphatic status and invasion in oral cancer. J Clin Pathol 61: 103-108, 2008

52. Stanton MJ, Dutta S, Zhang H, et al: Autophagy control by the VEGF-C/NRP-2 axis in cancer and its implication for treatment resistance. Cancer Res 73: 160-171, 2013.

53. Sullu Y, Demirag GG, Yildirim A, et al: Matrix metalloproteinase-2 (MMP-2) and MMP-9 expression in invasive ductal carcinoma of the breast. Pathol Res Pract 207: 747-753, 2011.

54. Takano S: Glioblastoma angiogenesis: VEGF resistance solutions and new strategies based on molecular mechanisms of tumor vessel formation. Brain Tumor Pathol 29: 73-86, 2012.

55. Takizawa H, Kondo K, Fujino H, et al: The balance of VEGF-C and VEGFR-3 mRNA is a predictor of lymph node metastasis in non-small cell lung cancer. Br J Cancer 95: 75-79, 2006.

56. Torii A, Kodera Y, Ito M, et al: Matrix metalloproteinase 9 in mucosally invasive gastric cancer. Gastric Cancer 1: 142-145, 1998.

57. Tsubata T: Apotosis of mature B cells. Int Rev Immunol 18 : 347-365, 1999.

58. Valtola R, Salven P, Heikkila P, et al: VEGFR-3 and its ligand VEGF-C are associated with angiogenesis in breast cancer. Am J Pathol 154: 1381-1390, 1999.

59. Vasala K, Paakko P and Turpeenniemi-Hujanen T: Matrix metalloproteinase-9 (MMP-9) immunoreactive protein in urinary bladder cancer: a marker of favorable prognosis. Anticancer Res 28: 1757-1761, 2008.

60. Vasala K and Turpeenniemi-Hujanen T: Serum tissue inhibitor of metalloproteinase-2 (TIMP-2) and matrix metalloproteinase-2 in complex with the inhibitor (MMP-2:TIMP-2) as prognostic markers in bladder cancer. Clin Biochem 40: 640-644, 2007

61. Wang F, Li HM, Wang HP, et al: siRNA-mediated knockdown of VEGF-A, VEGF-C and VEGFR-3 suppresses the growth and metastasis of mouse bladder carcinoma in vivo. Exp Ther Med 1: 899-904, 2010.

62. Wang Z, Li R, Zhou B, et al: Relationships of human laryngeal squamous cell carcinomas with the expression of VEGF-C and VEGFR-3. Sheng Wu Yi Xue Gong Cheng Xue Za Zhi 26: 842-846, 2009 (In Chinese).

63. Wu K, Wang X, Xie Z, et al: Glutathione S-transferase P1 gene polymorphism and bladder cancer susceptibility: an updated analysis. Mol Biol Rep 40: 687-695, 2013.

64. Yerlikaya A, Okur E and Ulukaya E: The p53-independent induction of apoptosis in breast cancer cells in response to proteasome inhibitor bortezomib. Tumor Biol 33: 1385-1392, 2012.

65. Yonemura Y, Fushida S, Bando E, et al: Lymphangiogenesis and the vascular endothelial growth factor receptor (VEGFR)-3 in gastric cancer. Eur J Cancer 37: 918-923, 2001.

66. Yu J and Zhang L: No PUMA, no death: implications for p53-dependent apoptosis. Cancer Cell 4: 248-249, 2003 
67. Yu J, Zhang L, Hwang PM, et al: PUMA induces the rapid apoptosis of colorectal cancer cells. Mol Cell 7: 673-682, 2001.

68. Zhang $\mathrm{C}$, Zhang $\mathrm{J}$, Zhang A, et al: PUMA is a novel target of miR-221/222 in human epithelial cancers. Int J Oncol 37: $1621-1626,2010$.

69. Zhang CZ, Zhang JX, Zhang AL, et al: MiR-221 and miR-222 target PUMA to induce cell survival in glioblastoma. Mol Cancer 9: 229, 2010

70. Zhang LN, Li JY and Xu W: A review of the role of Puma, Noxa and Bim in the tumorigenesis, therapy and drug resistance of chronic lymphocytic leukemia. Cancer Gene Ther 20: 1-7, 2013.
71. Zhao ZW, Wang JJ, Tang JS, et al: JNK- and Akt-mediated Puma expression in the apoptosis of cisplatin-resistant ovarian cancer cells. Biochem J 444: 291-301, 2012.

72. Zheng M, Zhang Q, Joe Y, et al: Curcumin induces apoptotic cell death of activated human $\mathrm{CD}^{+} \mathrm{T}$ cells via increasing endoplasmic reticulum stress and mitochondrial dysfunction. Int Immunopharmacol 15: 517-523, 2013.

73. Zhu X, Tai W, Shi W, et al: Matrix metalloproteinase-9 silencing by RNA interference promotes the adhesive-invasive switch in HT1080 human fibrosarcoma cells. Clin Lab 58: 313-322, 2012.

74. Nakano K and Vousden KH: PUMA, a novel proapoptotic gene, is induced by p53. Mol Cell 7: 683-694, 2001. 